THE KURUME MEDICAL JOURNAL Vol. 13, No. 2, 1966

\title{
FURTHER OBSERVATION ON THE MECHANISM OF THE REFLEX APNEA CAUSED BY NICOTINE. THE INFLUENCES OF SEVERAL BLOCKING AGENTS ADMINISTERED INTRAPERICARDIALLY ON THE NICOTINE APNEA
}

\author{
KOICHIRO TAKASAKI*
}

Department of Pharmacology, Kurume University School of Medicine, Kurume, Japan

(Received for publication September 8, 1966)

The previous experiments of Takasaki (1956), Takasaki et al. (1957, 1959b) have been shown that the mechanism of the reflex apnea caused by nicotine or diphenhydramine may be due to "pulmonary respiratory chemoreflex" as described by Dawes G.S. et al. (1954). Additionaly, the reflex systemic hypotension of veratrum alkaloids (Dawes, 1947, Aviado et al., 1951, Rose et al., 1957) is produced by a reflex from the lungs; it was called "pulmonary depressor chemoreflex" (Dawes et al. , 1954). This was confirmed with nicotine by Takasaki (1962).

The localization of receptors responsible for this reflex may be in the lung and this afferent path ascends in the vagi.

On the other hand, it has been shown that the reflex circulatory depressor responses and the impulses from heart receptors were intercepted by intrapericardial administration of procaine or local anesthetics (Kurotubo, 1942, Hukuda, 1951, Kido, 1953).

In the former experiment (Takasaki et al., 1959b), it was confirmed that the receptor in the heart is not responsible to the respiratory reflex caused by nicotine. It was also reported that the reflex apnea caused by nicotine was blocked by intravenous injection of tetraethylammonium bromide and hexamethonium bromide but not by atropine (Nakano et al., 1957, Takasaki et al., 1959a).

In this report, it was done attempting that the separation of the receptors in the heart and lungs using several blocking agents administered intrapericardially and the absorption of the drugs into the systemic circulation was investigated.

\section{METHODS}

This investigation was carried out on cats and rabbits anesthetized with $1 \mathrm{~g} / \mathrm{kg}$ of urethane, and on dogs anesthetized with $1 \mathrm{~g} / \mathrm{kg}$ of urethane and $3 \mathrm{mg} / \mathrm{kg}$ of morphine.

\footnotetext{
* Present address : Professor, Department of Pharmacology, Daiichi College of Pharmaceutical

Sciences, Fukuoka, Japan.
} 
The other experimental methods were carried out by the same methods as the previous reports (Takasaki, 1956, Takasaki et al. 1959b).

Tetraethylammonium bromide (TEA), hexamethonium bromide $\left(\mathrm{C}_{6}\right)$, atropine sulfate (atropine) and tolazoline (2-benzyl imidazoline hydrochloride, imidazoline) were used in this experiments and administered into the pericardial space prior to the intravenous or intra-rightventricular administration of nicotine in all species.

The nictitating membrane was arranged for recording of the contraction by electrical stimulation of cervical sympathetic nerve with a square wave stimulator (5 vlots, 30c/s), on smaked kymograph paper in the experiments of TEA or $\mathrm{C}_{6}$ in order to examine the absorption of these drugs into the systemic circulation from the pericardium.

\section{RESULTS}

\section{(A) Atropine}

The nicotine apnea (primary apnea) in almost cases was unaffected by the administration of $1 \%$ atropine into the pericardium space ranging from 1.5 to $4.5 \mathrm{ml}$ in the dogs (Fig. 1B), 0.3-0.5 $\mathrm{ml}$ in the cats, and $0.5-1 \mathrm{ml}$ in the rabbits.

The fall of blood pressure and heart rate caused by nicotine were almost abolished by atropine in the cats and dogs, and only the fall of blood pressure remained in the rabbits.

(A)

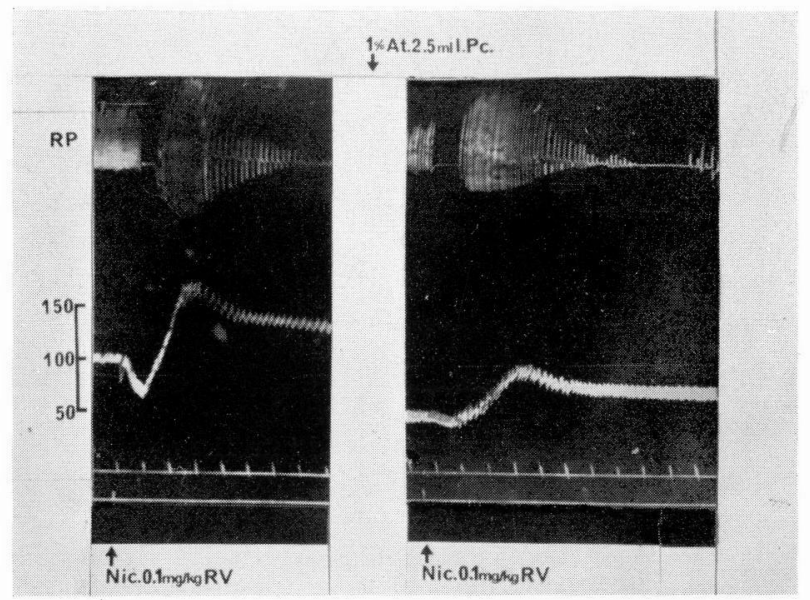

Fig. 1. Dog

A: Nicotine $0.1 \mathrm{mg} / \mathrm{kg}$ was injected into the right ventricle

B : Nicotine $0.1 \mathrm{mg} / \mathrm{kg}$ was injected into the right ventricle $10 \mathrm{~min}$ after intrapericardial administration of $1 \%$ atropine $2.5 \mathrm{ml}$.

RP: Respiratory movement with tambour (upper tracing).

Scale in $\mathrm{mmHg}$ of carotid arterial pressure (middle tracing).

Time interval : 10 seconds (lower tracing).

Arrow shows the injection of drugs.

Remarks are the same as those of Fig. 2,3 and 4 . 


\section{(B) Tolazoline}

Two $\%$ tolazoline was used in doses of $3 \mathrm{ml}$ in the dogs, $1.5-2.5 \mathrm{ml}$ in the cats, $0.5-1.3 \mathrm{ml}$ in the rabbits. The reflex apnea caused by nicotine was unaffected by the premedication of tolazoline into the pericardium before the injection of nicotine into the right ventricle while the bradycardia and fall of blood pressure was almost abolished after tolazoline in the cats and dogs.

On the other hand, the fall of blood pressure remained although the bradycardia was abolished completely in the rabbits.

\section{(C) Tetraethylammonium bromide (TEA)}

Ten $\%$ TEA was used and the different effects of the pretreatment of TEA intrapericardially were observed in three species. In the dogs, the reflex apnea caused by nicotine was blocked by TEA completely in doses of $0.75-1.5 \mathrm{ml}$ at 7 to $10 \mathrm{~min}$ before the administration of nicotine. However, in the cats, the nicotine apnea was not altered in doses of $0.1-4 \mathrm{ml}$ of TEA in most cases (Fig. 2B) although in 2 cases, this apnea was inhibited slightly. In the rabbits, similar to cats, the nicotine apnea was unaffected in doses of 0.05 to $0.35 \mathrm{ml}$ in almost cases, except a few rabbits in which this apnea was inhibited slightly (Fig.3B). The fall of blood pressure and bradycardia caused by nicotine were inhibited or abolished by TEA in all species.

(A)

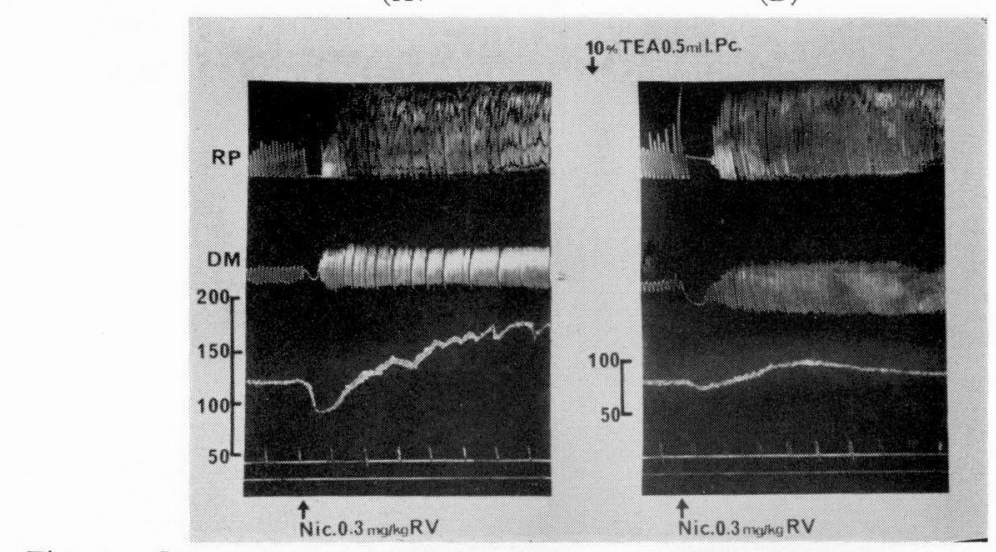

Fig. 2 Cat

A : Nicotine $0.3 \mathrm{mg} / \mathrm{kg}$ was injected into the right ventricle.

B : Nicotine $0.3 \mathrm{mg} / \mathrm{kg}$ was injected into the right ventricle $10 \mathrm{~min}$ after the intrapericardial administration of $10 \%$ TEA $0.5 \mathrm{ml}$.

DM : Respiratory movement of diaphragm using Hukuhara's method. Upwards, inspiratory ; downwards, expiratory.

This remark is the same as that of Fig. 3 and 4.

\section{(D) Hexamethonium bromide $\left(C_{6}\right)$}

The effects of the previous administration of $2.5 \% \mathrm{C}_{6}$ in doses of $1-1.5 \mathrm{ml}$ in the dogs, $0.2-0.6 \mathrm{ml}$ in the cats, $0.1-0.4 \mathrm{ml}$ in the rabbits into the pericardium within 3 $\min$ or at $7-10 \mathrm{~min}$ before nicotine was injected into the right ventricle were observed. The nicotine apnea did not occur in all species after $\mathrm{C}_{6}$. The fall of blood pressure and hẹart rate was also blocked by $\mathrm{C}_{6}$ and evẹn the sẹcondary rise of blood pressurę 
(A)

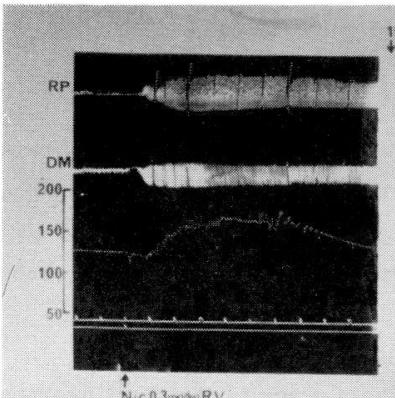

Nic03... RV
(B)

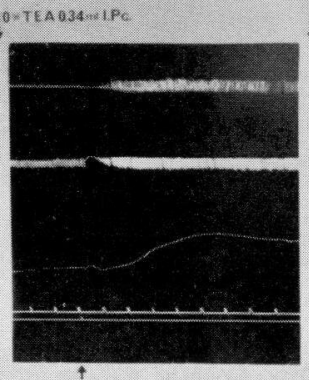

incosing
(C)

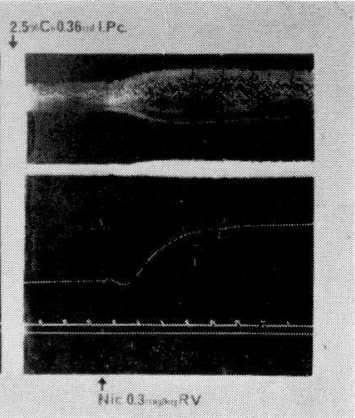

Fig. 3 Rabbit

A : Nicotine $0.3 \mathrm{mg} / \mathrm{kg}$ was injected into the right ventricle.

B : Nicotine $0.3 \mathrm{mg} / \mathrm{kg}$ was injected into the right ventricle $10 \mathrm{~min}$ after the intrapericardial administration of $10 \%$ TEA $0.34 \mathrm{ml}$.

C : Nicotine $0.3 \mathrm{mg} / \mathrm{kg}$ was injected into the right ventricle $10 \mathrm{~min}$ after the intrapericardial administration of $2.5 \% \mathrm{C}_{6} \quad 0.36 \mathrm{ml}$.

(A)

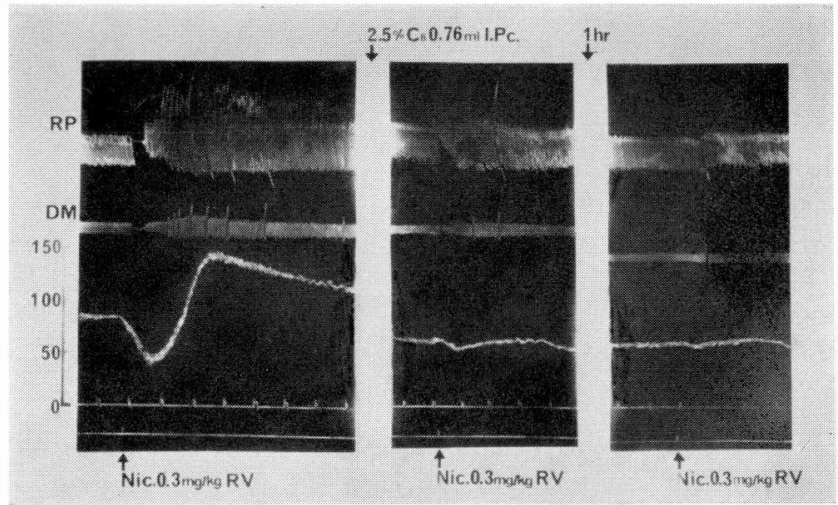

Fig. 4 Cat

A : Nicotine $0.3 \mathrm{mg} / \mathrm{kg}$ was in jected into the right ventricle.

B : Nicotine $0.3 \mathrm{mg} / \mathrm{kg}$ was injected into the right ventricle $3 \mathrm{~min}$ after $2.5 \% \mathrm{C}_{6} \quad 0.76 \mathrm{ml}$ intrapericardial administration.

C : Nicotine $0.3 \mathrm{mg} / \mathrm{kg}$ was injected into the right ventricle after $1 \mathrm{hr}$ from $B$.

caused by nicotine. The change in blood pressure caused by nicotine failed to occur entirely even after 3 min of $\mathrm{C}_{6}$ administration.

The following acceleration of respiration caused by nicotine was inhibited and was not clearly seen as in control. The above-mentioned results were similar to those obtained by the administration of $\mathrm{C}_{6}$ intravenously as described in the previous paper (Nakano et al., 1957, Takasaki et al., 1959a) (e.g., Fig. 3C, 4B and C). 
(E) The certification of the absorption from pericardium of $C_{6}$ and TEA using the contraction of the nictitating membrane with electrical stimulation of cervical sympathetic nerve.

In the previous paper, Takasaki et al. (1959b) demonstrated that the nicotine apnea was inhibited or abolished by procaine in large doses injected intrapericardially and suggested that this phenomenon is due to the absorption of procaine in the systemic circulation.

In this experiment, the contraction of the nictitating membrane with electrical stimulation of sympathetic nerve was examined after pericardial administration of $\mathrm{C}_{6}$ and TEA. As shown in Fig. 5, the contraction of the nictitating membrane was

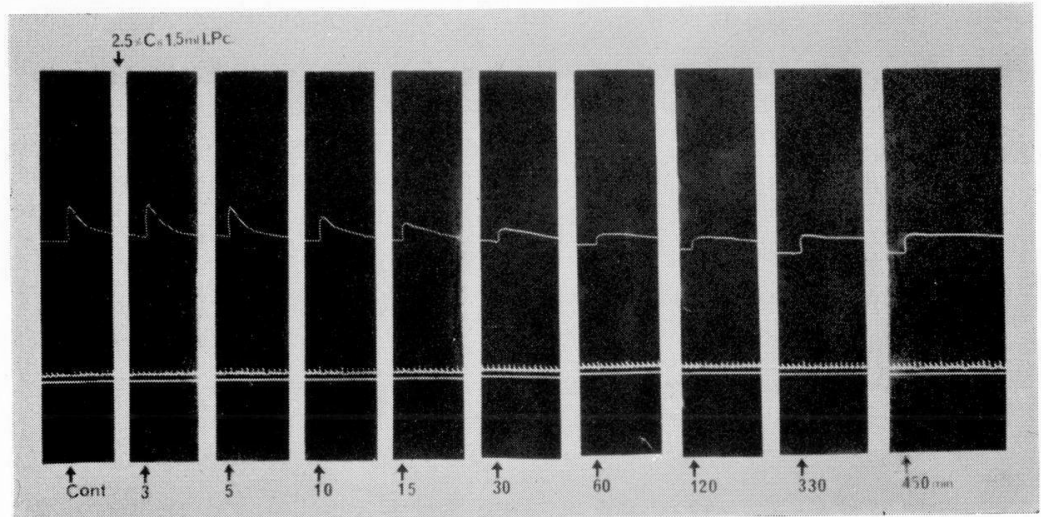

Fig. 5. Dog

The contraction of the nictitating membrane with the electrical stimulation (5 Volts, 30c/sec, $5 \mathrm{msec}$ ) of cervical sympathetic nerve at $3,5,10,15,30$, $60,120,330,450 \mathrm{~min}$ after the administration into the pericardium of $2.5 \%$ $\mathrm{C}_{6} 1.5 \mathrm{ml} . \mathrm{C}_{6}$ was injected intrapericardially between the first and second segment. Time interval : 10 seconds. Arrow shows the sympathetic nerve stimulation.

reduced gradually after the administration into the pericardium of $2.5 \% \mathrm{C}_{6} 1$ to 1.5 ml. This inhibition continued for $8 \mathrm{hrs}$ or more although the signs of recovery of the contraction appeared slowly 2 to $5 \mathrm{hrs}$ after the administration of the drug (Fig.5). In the similar experiments with $10 \%$ TEA 1 to $1.5 \mathrm{ml}$ the contraction of nictitating membrane was also reduced, however, it had a weaker effect than that after the administration of $\mathrm{C}_{6}$ and the contraction gradually recovered from 1.5 to $2 \mathrm{hrs}$ after the drug (Fig.6).

\section{DISCUSSION}

Domaye (1955), Nakano et al. (1957), Takasaki et al. (1959a) reported that the reflex apnea caused by nicotine was abolished completely with the administration of $\mathrm{C}_{6}$ or TEA $10 \mathrm{mg} / \mathrm{kg}$ or more intravenously in the cats and rabbits, $5 \mathrm{mg} / \mathrm{kg}$ or more in the dogs. In the present experiment, the reflex apnea caused by nicotine was 


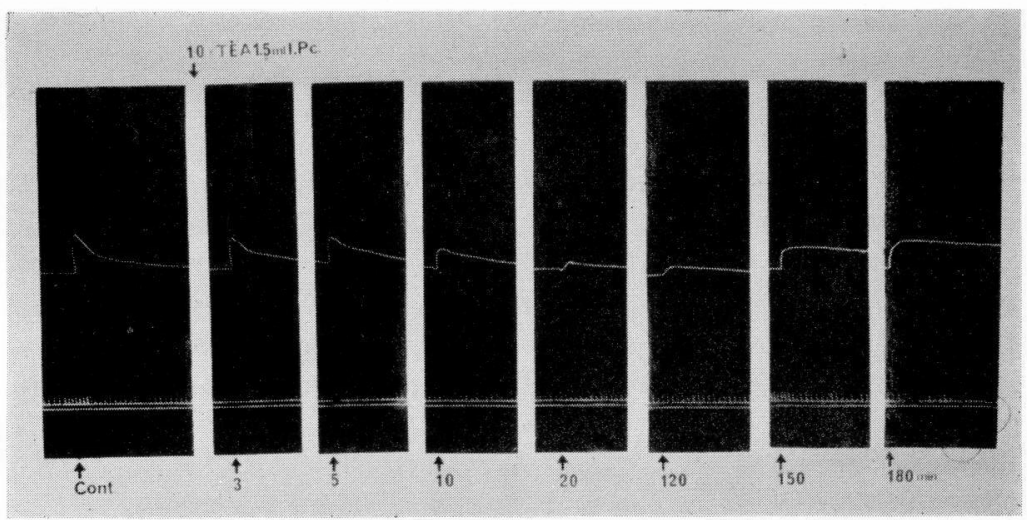

Fig. 6 Dog

The contraction of the nictitating membrane with the electrical stimulation as same as Fig. 5 at $3,5,10,20,120,150$, and $180 \mathrm{~min}$ after the administration of $10 \%$ TEA $1.5 \mathrm{ml}$ intrapericardially.

abolished by the administration of $\mathrm{C}_{6}$ into the pericardium in three species while the TEA produced a weak effect on the apnea in cats and rabbits whereas it was abolished in the dogs.

These blocking agents, in addition, have the effect of blocking the fall of blood pressure and bradycardia, and $\mathrm{C}_{6}$ has the blocking effect on the secondary rise of blood pressure also.

According to these results, it is imaginable that the receptors or ganglions connected with the reflex apnea caused by nicotine are located in the surface of the heart, and specially they were blocked by $\mathrm{C}_{6}$ immediately after the administration into the pericardium in comparison with the administration into the vein. However, the acceleration of respiration after nicotine apnea was strongly inhibited by $\mathrm{C}_{6}$ intrapericardially as well as intravenously. It seems likely that the blocking effects of nicotine apnea with $\mathrm{C}_{6}$ (or TEA) injected into the pericardium may be due to the infiltration into the surrounding tissues or the systemic circulation as shown with procaine (Takasaki et al., 1959b). The infiltration of $\mathrm{C}_{6}$ from the pericardium may be performed promptly and easily.

These evidences were also supported by the fact that the contraction of the nictitating membrane with the electrical stimulation of cervical sympathetic nerve was reduced by intrapericardial administration of $\mathrm{C}_{6}$ and TEA as same as intravenous injection of the drugs.

Therefore, it may be unreasonable to attempt the experiments with $\mathrm{C}_{6}$ without blocking the receptors in the lung and its reflex pathway as well as in the heart. The fall of blood pressure and bradycardia after the injection of nicotine into the right ventricle was not only abolished by $\mathrm{C}_{6}$ injected into the pericardium but also the secondary rise of blood pressure was blocked. It is suggested that this phenomenon was produced due to the infiltration from the pericardium by $\mathrm{C}_{6}$, moreover, the higher concentration of drugs was infiltrated near the receptor areas in the lung.

On the other hand, Takasaki et al. (1959) reported that the reflex apnea caused by nicotine was unaltered by small doses of procaine injected into the pericardium, 
nevertheless the fall of blood pressure and bradycardia was abolished completely in the dogs while the apnea was inhibited or abolished in large doses of procaine. It is probably due to the amount of procaine that escaped into the circulation from the pericardium. The receptors responsible for the fall of blood pressure and bradycardia are located on the surface of heart (endcardial receptors) while the receptor areas responsible for the reflex apnea caused by nicotine exist in other surrounding tissues, probably in the lungs. These facts show that the receptors in heart are not responsible for the respiratory reflex caused by nicotine.

Atropine administered into the pericardium has the same action as procaine and the intravenous injection of atropine and procaine (Semba, 1950, Nakano et al., 1957, Takasaki et al., 1959a) on the nicotine apnea. The apnea was unaffected by atropine usually. Therefore, the receptors in the heart responsible for the fall of blood pressure and heart rate, and receptors in the lungs responsible for the apnea were separated.

The intrapericardial administration of tolazoline abolished the fall of blood pressure and bradycardia caused by nicotine administered into the right ventricle while the apnea was unaffected by no means in doses as used in the experiment in three species. These results with atropine or tolazoline bring us a valuable procedure on the object of the experiments.

It was recognized that the location of the receptors responsible for the apnea caused by nicotine were presumably located somewhere within the pulmonary circulation in the lungs (Takasaki, 1956, Takasaki et al., 1959b).

The procedure of pericardial administration of several blocking agents in adequate doses may be a very valuable method in the separation of the location of receptors in the heart and lungs responsible for apnea caused by nicotine or other drugs.

The slight fall of blood pressure caused by nicotine when the apnea was not completely abolished in some cases, in all species after the blocking agents were injected into the pericardium. It might be suggested that the receptors for "pulmonary depressor chemoreflex" (Takasaki, 1962) were still responsible while the receptors in the heart was blocked.

\section{SUMMARY}

The effects of several blocking agents administered into the pericardium on the reflex apnea caused by nicotine were investigated in dogs, cats and rabbits and the obtained results as follows:

1. Hexamethonium bromide $\left(\mathrm{C}_{6}\right)$

The nicotine apnea and the change in blood pressure caused by nicotine were abolished completely and the acceleration of respiration was inhibited after $\mathrm{C}_{6}$.

The nictitating membrane with the electrical stimulation of cervical sympathetic nerve was reduced in three species.

2. Tetraethylammonium bromide (TEA)

The fall of blood pressure and bradycardia was inhibited or abolished by the administration of TEA before nicotine in three species, and the nicotine apnea was abolished in all dogs and in most cats and rabbits. The nicotine apnea was unaffected in a few cats and rabbits, even in higher doses of TEA. These results may indicate that the large doses of TEA might be required in comparison with the 
doses of $\mathrm{C}_{6}$ to abolish the apnea.

The contraction of the nictitating membrane was reduced after TEA in three species.

3. Atropine and tolazoline

The nicotine apnea was unaffected by the administration of atropine or tolazoline in three species.

Above-mentioned results suggested that the receptors in heart are not responsible for the apnea caused by nicotine.

Furthermore, the absorption of the drugs from the pericardium in the systemic circulation was discussed.

\section{REFERENCES}

1) Aviado, D. M. JR. , Li, T. H. , Kalow, W. , Schmidt, C. F. , Turnbull, G. L. , Peskin, G. W. , HEss, M.E. AND WeIss, A. J. : Respiratory and circulatory reflexes from the perfused heart and pulmonary circulation of the dog. Am. J. Physiol., 165, 261-277, 1951.

2) DAwes, G.S. : Studies on veratrum alkaloid. J. Pharmacol. , 89, 325-342, 1947.

3) Dawes, G.S. and Comroe, J.H. JR. : Chemoreflexes from the heart and lungs. Physiol. Rev., 34, 169-201, 1954.

4) DomAYe, A. : On the action of nicotine upon respiration with particular reference to its blockade by hexamethonium. Jap. J. Pharmacol. , 5, 1-10, 1955.

5) Hukuda, T. : On the cardiac reflex. Seitai-no-kagaku, 2, 2-7, 1951 (in Japanese).

6) KIDo, R. : On the effects of drugs on the afferent impulses from the heart (Studies on the cardiac reflex III). Kyushu Memoirs Med. Sci., 3, 149-159, 1953.

7) Kurotubo, M. : The cardiac, vascular and respiratory reflex from the heart, especially on its pharmacological meaning. Folia Pharmacol. Japon., 34, 300-330, 1942. (in Japanese).

8) Nakano, T., Takasaki. K, .OTA, K. AND NAgasaki, N. : The effects of several blocking agents on reflex apnea caused by nicotine or diphenhydramine. This Journal, 4, 49-52, 1957.

9) Rose, J.C. and LAzARo, E. J. : Veratrum hypotension due to reflexes of pulmonary origin. J. Pharmacol., 119, 324-328, 1957.

10) Semba, T. : Studies on the action of nicotine to the blood pressure. J. Physiol. Soc. Japan., 13, 203-210, 1950 (in Japanese).

11) TAKASAKI, K. : The mechanism of the reflex apnea caused by nicotine, especially on the species difference between cat and rabbit. This Journal, 3, 146-159, 1956.

12) TAKasaki, K., Sakai, K., OTA, K. AND NAgASAKI, N. : The mechanism of the respiratory and circulatory reflex caused by nicotine and diphenhydramine. : The effects of several blocking agents on the reflex in dogs. Ibid. 6, 98-103, 1959a.

13) TAKasaki, K. , Sakai. K., MiYazaki, N. AND NAgasaki, N. : The mechanism of the reflex apnea caused by nicotine. : Influences of intrapericardially injected procaine on the apnea in cats, rabbits and dogs. Ibid., 6, 104-109, 1959b.

14) TAKASAKI, K. : Arterial pressure changes by drugs injected into isolated pulmonary circulation in dogs. Am. J. physiol., 203, 947-950, 1962. 